\title{
Epidemiological Analysis of Surgically Treated Acute Traumatic Epidural Hematoma
}

\author{
Aurelien Ndoumbe ${ }^{1 *}$, Martine Virginie Patience Ekeme ${ }^{2}$, Bonaventure Jemea ${ }^{3}$, \\ Chantal Simeu3 ${ }^{3}$, Samuel Takongmo ${ }^{4}$ \\ ${ }^{1}$ Faculty of Medicine \& Pharmaceutical Sciences, University of Douala, Douala, Cameroon \\ ${ }^{2}$ District Medical Hospital of Logpom, Douala, Cameroon \\ ${ }^{3}$ Service of Anesthesiology \& Intensive Care, University Hospital Center of Yaoundé, \\ Yaoundé, Cameroon \\ ${ }^{4}$ Faculty of Medicine \& Biomedical Sciences, University of Yaoundé I. Head, Service of Surgery, University \\ Hospital Center of Yaoundé, Yaoundé, Cameroon \\ Email: "aurelien.ndoumbe@gmail.com, *aurelen@yahoo.fr
}

Received 21 April 2016; accepted 27 June 2016; published 30 June 2016

Copyright (C) 2016 by authors and Scientific Research Publishing Inc.

This work is licensed under the Creative Commons Attribution International License (CC BY). http://creativecommons.org/licenses/by/4.0/

C) (i) Open Access

\section{Abstract}

This study is a retrospective analysis of demographic, clinical, radiological and outcome data of surgically treated acute traumatic epidural hematomas. Forty-six consecutive cases of epidural hematomas were operated at the University Hospital Center of Yaoundé, Cameroon, between February 2006 and December 2013. The mean age was 29.56 years and63.04\% of patients were between 21 and 30 years. Almost $94 \%$ of patients were males. Thirty-five percent of patients were motorcycle riders. Road traffic accident was the cause in $\mathbf{7 0 \%}$ of cases. Mean time between head trauma and surgical evacuation was 78 hours. Head trauma was moderate in $\mathbf{5 2 . 1 7 \%}$. Initial loss of consciousness was found in $78.26 \%$ and lucid interval in $65.23 \%$. Seventy-four percent of patients had signs of intracranial hypertension on admission, $35 \%$ had at least one neurologic focal sign and $50 \%$ had a scalp wound. Eight patients $(17.39 \%)$ presented with unilateral or bilateral mydriasis. On computed tomography, the hematoma was on the left side in $60.86 \%$ of patients and frontal-parietal location was the most frequent. Computed tomography showed mass effect in $\mathbf{9 7 . 8 2 \%}$ of patients. The most frequent surgical procedure was craniotomy. Six $(13.04 \%)$ patients died, but $82.60 \%$ recovered fully (GOS 5). In Cameroon, traumatic acute epidural hematoma affects primarily healthy young men in their twenties and thirties. Road traffic accidents are the main etiology. Most patients had moderate head trauma and presented with intracranial hypertension. Early surgery is rarely done. Nevertheless, even with delayed surgery, most patients have good outcome.

\footnotetext{
${ }^{*}$ Corresponding author.
}

How to cite this paper: Ndoumbe, A., Ekeme, M.V.P., Jemea, B., Simeu, C. and Takongmo, S. (2016) Epidemiological Analysis of Surgically Treated Acute Traumatic Epidural Hematoma. Open Journal of Modern Neurosurgery, 6, 89-97. http://dx.doi.org/10.4236/ojmn.2016.63016 


\section{Keywords}

\section{Head Trauma, Epidural Hematoma, Epidemiology, Delayed Surgery, Outcome}

\section{Introduction}

Traumatic brain injury (TBI) or head trauma is a major public health issue worldwide because it is the leading cause of death for patients between second and fourth decades. Epidural or extradural hematoma (EDH), which is a collection of blood between the inner table of skull and dura mater occurs in 1\% - 5\% of TBI. The classical presentation of EDH comprises a brief loss of consciousness (LOC), followed by a lucid interval of several hours, then, obtundation with focal neurologic signs. Untreated EDH can progress to coma, and eventually death. High risk factors for traumatic EDH include male gender, age between 20 - 30 years and activities at risk such as road traffic, falls, sports and physical assaults [1]-[7]. EDH is a neurosurgical emergency which warrants prompt surgical removal. Some studies have addressed the epidemiology of patients with EDH who need surgery. The goal of this study is to report on epidemiological analysis of acute traumatic EDH surgically treated at the University Hospital Center (UHC) of Yaoundé, Cameroon. Age, gender, mode of injury, localization, clinical presentation, computed tomography (CT) findings, surgical procedures and outcome data were retrospectively reviewed.

\section{Patients and Methods}

An epidemiological analysis of 46 patients operated upon for acute traumatic EDH was done. Age, gender, mechanism of injury, site of hematoma, clinical presentation, CT findings, operative procedures and outcome data were retrospectively collected from patients' medical records and reviewed. Severity of the trauma was determined by initial Glasgow coma scale (GCS) score on admission (Table 1). The Glasgow outcome scale (GOS, Table 2) was used to evaluate neurological outcome and was determined at discharge from hospital. Factors known to influence prognosis of EDHs were checked.

All consecutive cases of traumatic acute EDH operated on between February 2006 and December 2013 at the UHC of Yaoundé were included in the study. Non traumatic EDHs, traumatic EDHs treated conservatively and EDHs with incomplete medical records were excluded.

Patients were operated under general anesthesia with oral tracheal intubation. The size, shape and location of

Table 1. Glasgow coma scale.

\begin{tabular}{lll}
\hline \multicolumn{1}{c}{ Eye opening (E) } & \multicolumn{1}{c}{ Verbal response $(\mathbf{V})$} & \multicolumn{1}{c}{ Motorresponse (M) } \\
\hline $4=$ Opens spontaneously & $5=$ Normal conversation & 6 = Normal, obeys to command \\
$3=$ Opens to voice & $4=$ Confused, disoriented & $5=$ Localizes pain \\
$2=$ Opens to pain & $3=$ Incoherent, inappropriate & $4=$ Withdraws from pain \\
$1=$ None & $2=$ Incomprehensible & $3=$ Decorticate posturing \\
& $1=$ None & 2 Decerebrate posturing \\
\hline
\end{tabular}

Score $=\mathrm{E}+\mathrm{V}+\mathrm{M}$. Minimum = 3. Maximum $=15$

Table 2. Glasgow outcome score.

\begin{tabular}{cc}
\hline Score & Definition \\
\hline 1 & Dead \\
2 & Permanent vegetative state \\
3 & Severedisability, dependent \\
4 & Moderatedisability but independent \\
5 & Good recovery \\
\hline
\end{tabular}


the skin incision and bone flap were tailored according to the site of the hematoma. Most EDHs were evacuated via a craniotomy (bone flap repositioned after evacuation of the EDH), some by a craniectomy (expanded burr hole) and very few by simple burr hole. EDH was removed with smooth suction. Adherent clots were not necessarily removed for avoiding bleeding. Whenever identified, the bleeding vessel was coagulated. If the dura seemed tensed and bluish, a small incision was made through it to look for an associated subdural hematoma. At the end of the procedure, the dura was stacked to the bone with sutures. In most patients, the epidural space was not drained. After repositioning of the bone flap, in case of craniotomy, the skin was closed in layers.

The study had an ethical committee approval and informed consent was obtained from patients or their families.

The statistical analysis was done with the software SPSS 16.0 for windows. The Fisher and the Chi-square tests were used. Statistical significance was set for p value $<0.05$.

\section{Results}

\subsection{Sociodemographic Data}

Forty-three (93.48\%) patients were males and only three were females. The mean age was $29.56 \pm 7.69$ years, range, 11 to 60 years. The third decade was the most represented with 29 (63.04\%) patients. No patient below 11 or above 60 years of age. Second, third and fourth decades comprised $87 \%$ of all patients. Age distribution is detailed on Figure 1. Sixteen (34.78\%) patients were motorcycle's riders. Road traffic accident was the most frequent mechanism of TBI (Table 3).

\subsection{Clinical Data}

The past medical history was unremarkable for 42 (91.30\%) patients. On admission, 36 (78.26) patients had mild to moderate TBI (GCS 9 - 15) and ten patients were comatose. The classical depiction of initial loss of consciousness (LOC) followed by a lucid interval before neurological deterioration was observed in most cases. Thirty-six (78.26\%) patients further deteriorated neurologically between admission and operation. See Table 3 for details.

\subsection{Radiological Data}

All patients had brain CT scanning which confirmed the diagnosis of EDH in 100\% of cases. EDH was located

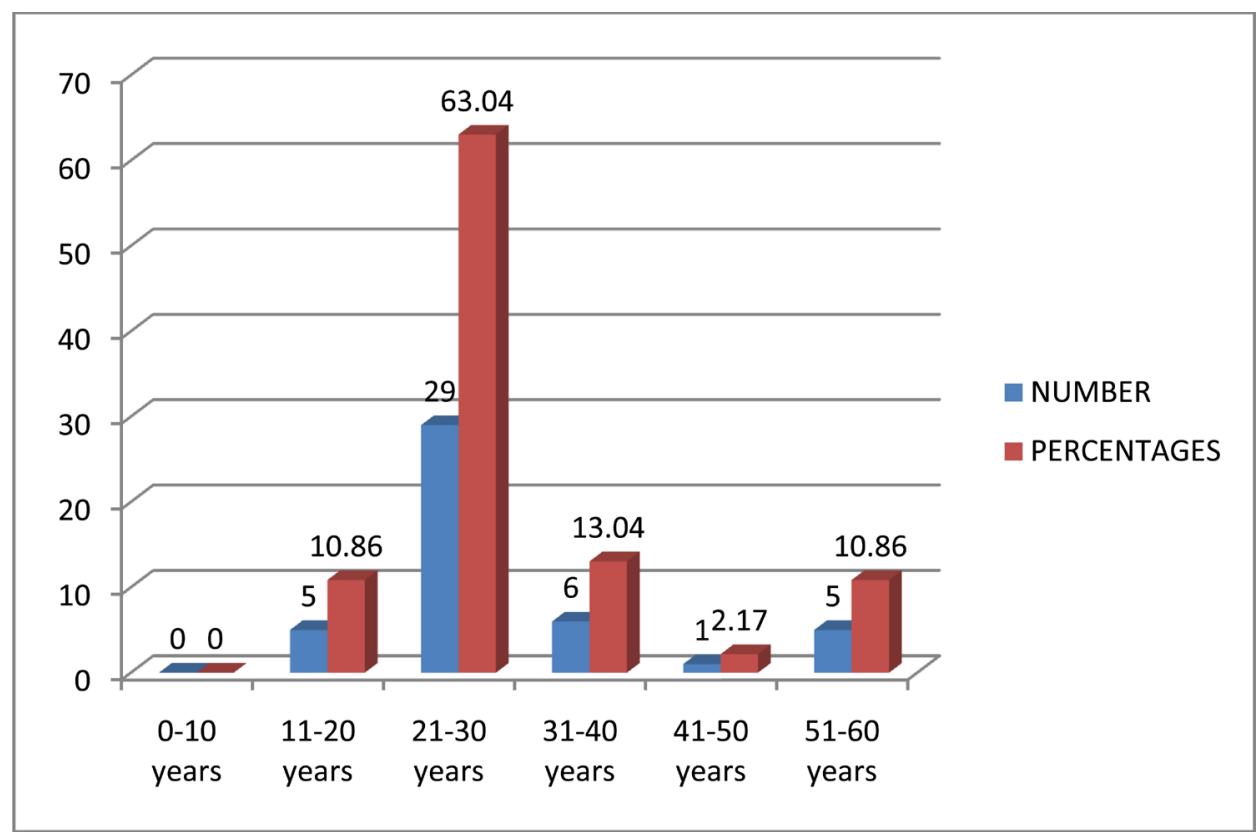

Figure 1. Age distribution of patients with extradural hematomas. 
Table 3. Demographic and clinical profile of acute traumatic epidural hematomas.

\begin{tabular}{|c|c|c|}
\hline Features & Number (n) & Percentages \\
\hline Number of patients & 46 & \\
\hline $\begin{array}{l}\text { Gender } \\
\text { Male } \\
\text { Female } \\
\text { Male: female ratio }\end{array}$ & $\begin{array}{l}43 \\
03\end{array}$ & $\begin{array}{l}93.48 \\
06.52 \\
\text { 14.33: } 1\end{array}$ \\
\hline $\begin{array}{l}\text { Mode of injury } \\
\text { Road traffic accident } \\
\text { Assaults } \\
\text { Fall }\end{array}$ & $\begin{array}{l}32 \\
12 \\
02\end{array}$ & $\begin{array}{l}69.56 \\
26.09 \\
04.35\end{array}$ \\
\hline $\begin{array}{l}\text { Clinical presentations } \\
\text { Altered sensorium } \\
\text { Headache/vomiting } \\
\text { Initial LOC } \\
\text { Lucid interval } \\
\text { Neurodeficit } \\
\text { Pyramidal signs } \\
\text { Mydriasis (unilateral; bilateral) } \\
\text { Sympathetic storming } \\
\text { Scalp wound } \\
\text { Associated extra cranial injuries }\end{array}$ & $\begin{array}{l}32 \\
30 \\
36 \\
30 \\
16 \\
10 \\
08(5 ; 3) \\
16 \\
23 \\
05\end{array}$ & $\begin{array}{l}69.56 \\
65.21 \\
78.26 \\
65.21 \\
34.78 \\
21.74 \\
17.39(10.87,06.52) \\
34.78 \\
50.00 \\
10.87\end{array}$ \\
\hline $\begin{array}{l}\text { GCS scores at admission } \\
\text { GCS } 14-15 \\
\text { GCS } 9-13 \\
\text { GCS } \leq 8 \\
\text { Further neurological deterioration }\end{array}$ & $\begin{array}{l}12 \\
24 \\
10 \\
36\end{array}$ & $\begin{array}{l}26.08 \\
52.17 \\
21.74 \\
78.26\end{array}$ \\
\hline $\begin{array}{l}\text { CT findings } \\
\text { Mass effect (midline shift) } \\
\text { Associated craniocerebral injury } \\
\text { Skull fracture } \\
\text { Calvaria } \\
\text { Depressed } \\
\text { Skull base } \\
\text { Subfalcine herniation }\end{array}$ & $\begin{array}{l}45 \\
45 \\
34 \\
28 \\
12 \\
06 \\
18\end{array}$ & $\begin{array}{l}97.82 \\
97.82 \\
73.91 \\
60.86 \\
26.08 \\
13.04 \\
40.00\end{array}$ \\
\hline Mortality & 06 & 13.04 \\
\hline
\end{tabular}

LOC: loss of consciousness; GCS: Glasgow coma scale; CT: computed tomography.

on left side in 28 (60.87\%) and on right side in 18 (39.13\%) of the cases. All hematomas were supratentorial and the frontal-parietal location was the most frequent. The frontal region was involved alone or in combination in 31 (67.39\%) cases, the parietal region in 25 (53.34\%) and temporal region in 23 (50\%) patients respectively (Figure 2).

Because of the retrospective aspect of this study, the volume of EDHs was not calculated, though its thickness was recorded. The mean thickness was $22.40 \mathrm{~mm}$, range; 8 - $44 \mathrm{~mm}$. EDH was greater than mean thickness in $60.86 \%$ (28) of patients. In 43 (93.47\%) patients, hematoma thickness was more than $10 \mathrm{~mm}$.

Mass effect was seen in 45 (97.82\%) and subfalcine herniation was present in 18 (40\%) patients respectively. All patients but one had associated craniocerebral lesions with the EDH. A skull fracture was present in 34 (73.91\%) patients. These lesions are detailed in Figure 3.

\subsection{Operative Data}

The mean time between trauma and surgical evacuation of EDH was 78 hours, range, 1 - 16 days. Thirty-one (67.39\%) patients were operated before 72 hours post-injury, but 15 (32.61\%) after this time lag. Types of operations were as follows: craniotomy, 53.3\%; craniectomy (expanded burrhole), $26.7 \%$ and burr hole, $20 \%$.

\subsection{Outcome}

Outcome was evaluated using the GOS at discharge from hospital. Six (13.04\%) patients died, but 38 (82.61\%) 


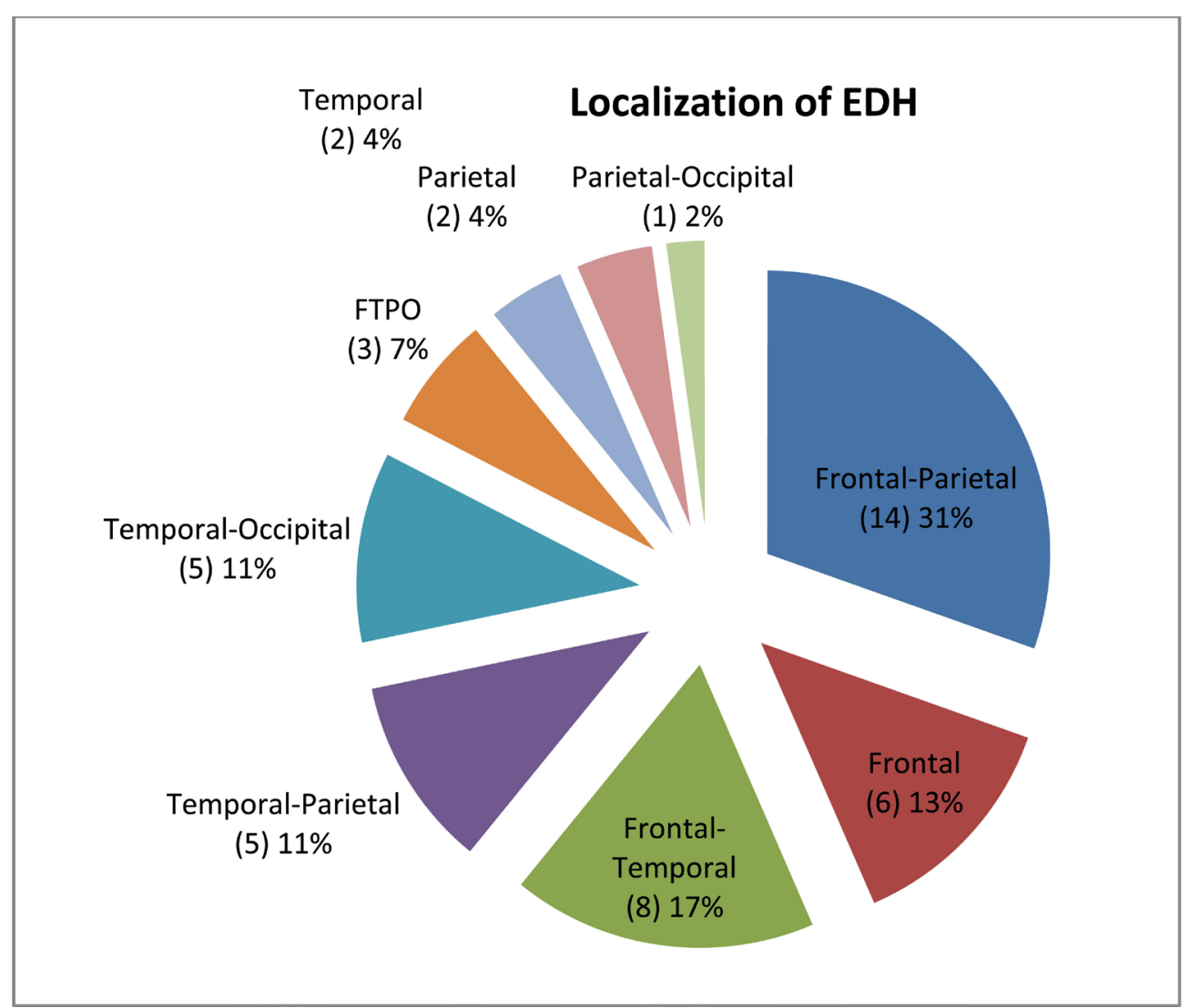

Figure 2. Sites of epidural hematoma (EDH). (FTPO: frontal-temporal-parietal-occipital).

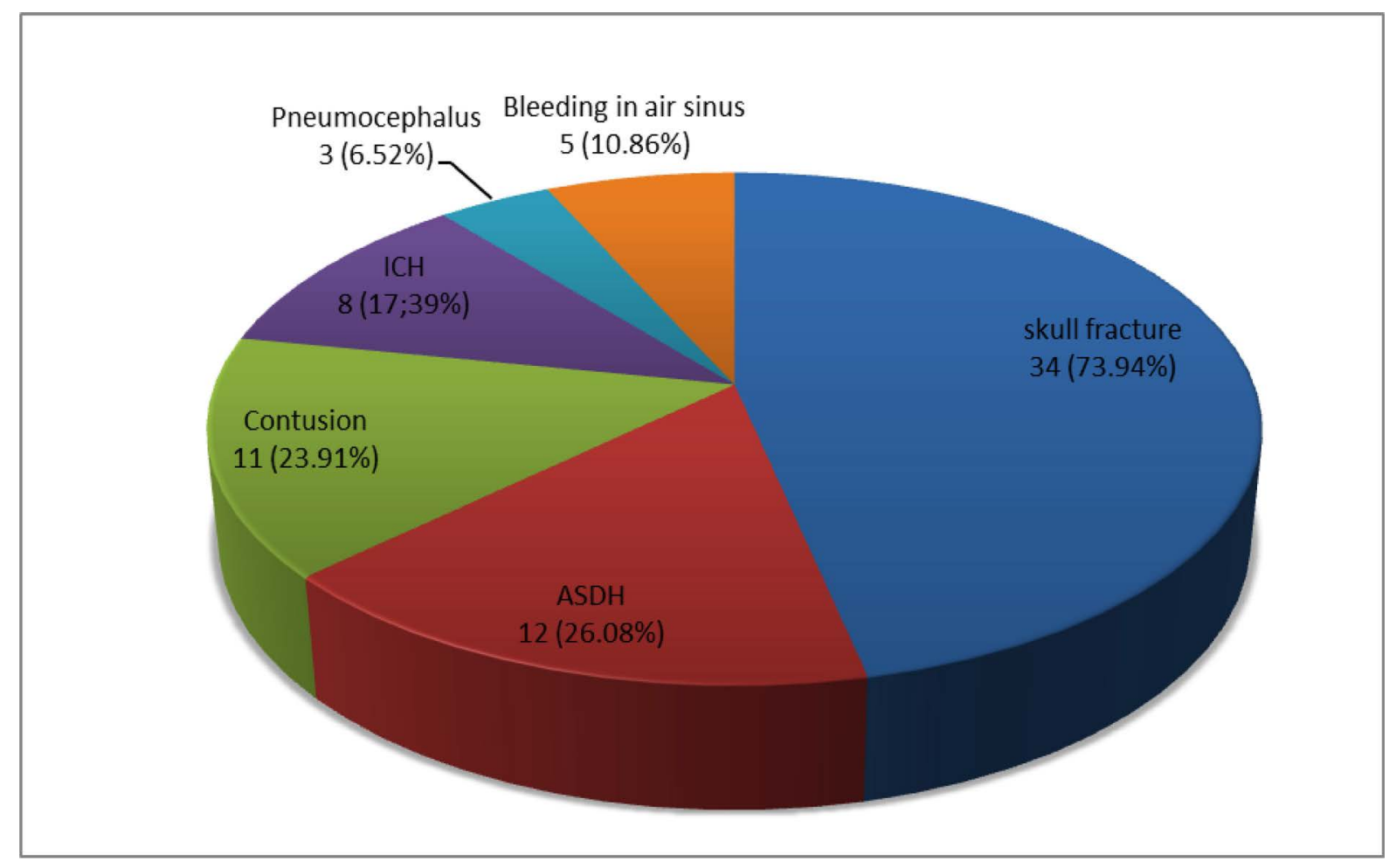

Figure 3. Craniocerebral injuries associated with EDHs. (ASDH, acute subdural hematoma. ICH, intracerebral hematoma). 
had good recovery (Figure 4). Mean hospital stay was 7.06 days, median, 12 days, range, 1 - 23 days. There was no post-operative complication.

\section{Discussion}

Most findings from this series such as age, gender, cause of trauma, were consistent with data from literature [1]-[5]. There are few peculiarities about male predominance, frequency of LOC and lucid interval.

\subsection{Age Distribution}

Mean age was 29.56 years and third decade represented $63 \%$ of patients. Second, third and fourth decades were the most involved and accounted for $86.94 \%$ of patients. This age distribution is consistent with data from other authors [1]-[6]. The people in these age groups are in the most active period of life and they are therefore involved in activities at risk for head trauma. It is known that EDH is rare before two years and after 60 years of age [1]. In this operative series, EDH was not observed in patients under 11 years and over 60 years of age.

\subsection{Gender}

Male predominance for EDH is unanimously reported from literature suggesting that males are more exposed to activities at risk for TBI [1]-[7]. In this series, male predominance was even more pronounced with 93.48\% of male patients giving a sex ratio of 14.33:1. So, male gender was a high risk factor for being operated upon for acute traumatic EDH $(\mathrm{P}<0.0001)$.

\subsection{Cause of Trauma}

Road traffic accidents were the first mechanism of trauma in this series followed by assaults. Depending on the series, the three main modes of injury for traumatic EDHs are; RTA, falls and assaults in different variations [2]-[7].

\subsection{Severity of TBI}

Classifying severity of TBI in any way is arbitrary. We used the classification proposed by Greenberg: GCS 14 15, mild TBI, GCS 9 - 13, moderate TBI, GCS $\leq 8$, severe TBI [1]. In that manner, 78.26\% $(\mathrm{n}=36)$ of patients had mild or moderate head injury on admission (26.09\% mild and 52.17 moderate TBI), suggesting that EDHs result from low energy impact. This is in agreement with other series [2] [4] [5]. Out of16 patients who had GCS

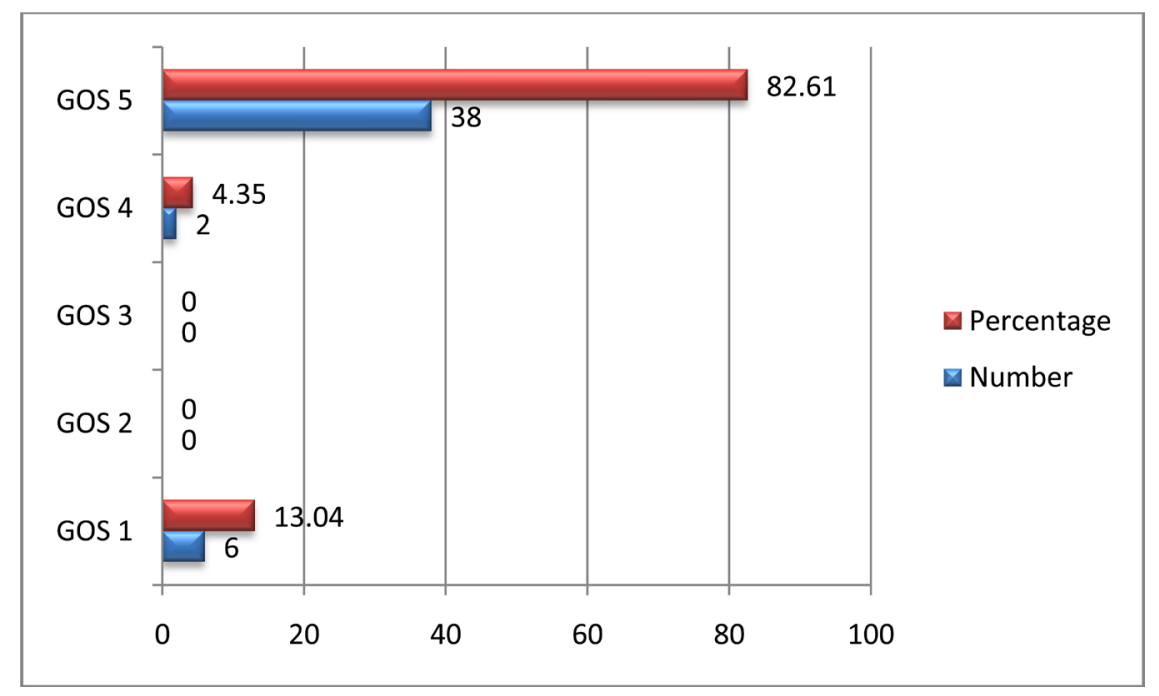

GOS 1, dead. GOS 2, permanent vegetative state. GOS 3, severe disability, dependent.GOS 4, moderate disability, independent. GOS 5, good recovery. 
of 13 - 15 on admission, one died and 11 (68.75\%) of them neurologically deteriorated before surgery. Therefore, significant EDH even without decreased sensorium on admission is prone to undergo the classical depiction with lucid interval followed by neurological deterioration, if not treated promptly.

\subsection{Clinical Data}

The mode of presentation of traumatic EDHs in this series was altered sensorium in 32 (69.56\%) and headache/ vomiting in 30 (65.21\%) patients respectively and ten (21.74\%) patients were comatose. This corroborates with the series from Mezue et al., Chowdhury Noman et al. and others [2]-[6]. Initial LOC was noticed in 36 (78.26\%) of the cases. This high frequency of LOC is in disagreement with Greenberg [1] for who no initial LOC occurs in 60\%. However, Ozkan et al. [6] had reported LOC in $67.82 \%$.

Lucid interval was observed in 30 (65.21\%) patients in this series. This is very high compared to data from other authors [3] [5]-[7]. For Greenberg, there is no lucid interval in 20\%, but he did not clearly say that lucid interval was present in the remaining $80 \%$ [1]. High frequency of lucid interval in this series may be explained by long delay between trauma and surgery, giving enough time for the natural course of the disease to go on and classical depiction to be observed. Out of 16 patients admitted with GCS of 13 - 15, eleven (68.75\%) further deteriorated before surgery.

Eight (17.39\%) patients had unilateral (05) or bilateral (03) mydriasis. For Greenberg, 60\% of patients with EDHs had a dilated pupil [1]. Incidence of pupillary changes is diversely reported [3] [5] [6].

Other intracranial injuries such as acute subdural hematomas, contusions/ICH were associated to acute EDH in 31 (67.39\%) patients. This percentage is high compared to those from other series in which $16.52 \%-32.8 \%$ of patients with traumatic EDHs also had intracranial injuries [4] [6] [7]. Hemorrhagic contusions or ICH and ASDH were found in 19 (41.30\%) and 12 (26.08\%) cases respectively. These percentages are also high compared to those from other series [1] [3] [4].

\subsection{CT Scan Findings}

EDH was diagnosed in all patients by brain CT scan. Besides EDH and other intracranial injuries, CT scan showed skull fracture in 34 (73.91\%) patients. Chowdhury et al. [3] reported 74.09\% skull fractures in their series. The incidence of skull fractures in other series, although lower, was equally significant [4] [7].

In most series, the temporal-parietal region is the most common site of EDHs [2]-[7]. This is in disagreement with this study in which the frontal-parietal site was most frequently involved with the frontal region most often involved than the temporal. Involvement of the frontal region in most cases of this series may be explained by the fact that most patients were motorcycle riders who were not wearing helmets. Therefore, the frontal area may have been the impact zone in most patients. The high incidence of skull fractures and involvement of the frontal region may explain why most of our patients had good recovery in spite of the very long delay between trauma and surgical evacuation of EDHs. It is known that hematoma can sour through fracture lines, thus decreasing intracranial hypertension. It is equally known that the outcome of frontal EDHs is better than temporal ones [3] [5]-[7]. Nonetheless, the influence of cranial fracture and hematoma site on outcome is still debated.

\subsection{Surgery}

Surgical evacuation of EDHs was delayed in most cases because of the late arrival of patients or lack of financial resources which prevented CT scanning and surgical intervention to be done in time. The mean time between trauma and operation was 78 hours in this series. This is lower than the average time lag of 94.2 hours between TBI and surgery reported by Mezue et al. in Nigeria [2]. In this series, 36.95\% of patients were operated within 24 hours after trauma, which is similar to the $37.68 \%$ of patients operated within 24 hours after trauma by Mezue et al. [2]. We disagree with Mezue et al. who stated that late presentation in their series was due to delayed EDHs. Since EDHs were not ruled out by previous CT scans in patients who presented late in their study therefore, diagnoses of delayed EDHs do not seem accurate. In Sub-Saharan Africa, late presentation is likely to be attributed to poor transportation facilities, poor organization of the health care system, low income, and lack of public health insurance, which delay patients with traumatic EDHs to reach appropriate health care in time. Early and prompt evacuation of significant and symptomatic EDHs is universally accepted as one of the crucial factors for improving outcome of TBI patients with EDHs [1]-[7]. 


\subsection{Outcome}

Six (13.04\%) patients died. This is within mortality rates reported in the CT scan era [1]-[7]. This mortality rate is even lower to what could be expected, considering that surgical evacuation of EDHs in this series was delayed in most patients due to non-medical reasons.

Thirty eight (82.61\%) patients recovered with no disability (GOS, 5) and two (04.35\%) had moderate disability but were independent (GOS, 4). This high percentage of good recovery in a series in which surgery was delayed may be explained by the fact that most patients $(36,78.60 \%)$ were admitted with mild to moderate TBI. Many authors had reported zero mortality for patients with GCS of 13 or above [2] [5] [6]. The high percentage of good recovery in a surgical series of EDHs with delayed evacuation suggests that even with late presentation, surgery is the best option for significant and symptomatic EDHs.

In this series, outcome was influenced by GCS score upon admission ( $\mathrm{p}=0.0001)$, midline shift with subfalcine herniation $(p=0.004)$ and hematoma thickness $(p=0.03)$. All patients but one who died was comatose $(\mathrm{GCS} \leq 8)$. Mortality was $0 \%$ for GCS $14-15,08.33 \%$ for GCS $9-13$ and $50 \%$ for GCS $\leq 8(p=0.0001)$. The GCS score is unanimously recognized as one of the major prognostic factor for the outcome of patients with traumatic EDHs [1]-[3] [5]-[7].

Surprisingly, neither pupillary abnormality nor delay between trauma and surgery among other factors had an effect on the outcome in this series. Many factors have been identified as prognosticators for patients with traumatic EDHs. Some are unanimously admitted while others are controversial [1]-[7]. Discussion on prognostic factors for surgically treated acute traumatic EDHs is beyond the scope of this article.

\section{Conclusion}

In Cameroon, acute traumatic epidural hematoma primarily affects healthy young men in their twenties and thirties with unremarkable past medical history. Road traffic accidents are the first mode of injury. Most patients had mild or moderate head trauma and presented with headache, vomiting oraltered sensorium. Initial LOC and lucid interval are noticed in most cases. Most patients will further deteriorate while waiting for surgery. The hematoma is most often located on the left side and the frontal-parietal area is the most involved site. Brain CT scan makes the diagnosis in $100 \%$ of patients. Surgery is often delayed for many days due to extra medical factors. Bone flap craniotomy is the most frequent procedure. But, even with this delayed surgery, most patients have a good outcome. Therefore, surgical evacuation is still the best treatment option for significant symptomatic acute EDHs though with late presentation.

\section{Conflict of Interest}

None.

\section{References}

[1] Greenberg, M.S. (2001) Epidural Hematoma. In: Handbook of neurosurgery, 5th Ed. Thieme Medical Publishers, New York, 660-662.

[2] Mezue, W.C., Ndubuisi, C.A., Chikani, M.C., Achebe, D.S. and Ohaegbulam, S.C. (2012) Traumatic Extradural Hematoma in Enugu, Nigeria. Nigerian Journal of Surgery, 18, 80-84.

[3] Chowdhury Noman Khaled, S.M., Raihan, M.Z., Chowdhury, F.H., Ashadullah, A.T.M., Sarkar, M.H. and Hossain, S.S. (2008) Surgical Management of Traumatic Extradural Haematoma: Experience with 610 Patients and Prospective Analysis. Indian Journal of Neurotrauma (IJNT), 5, 75-79.

[4] Araujo, J.L.V., Aguiar, U.P., Todeschini, A.B., Saade, N. and Veiga, J.C.E. (2012) Epidemiological Analysis of 210 Cases of Surgically Treated Traumatic Extradural Hematoma. Revista do Colégio Brasileiro de Cirurgiões, 39, 268271. http://dx.doi.org/10.1590/S0100-69912012000400005

[5] Yurt, I., Bezircioglu, H., Ersahin, Y., Demircivi, F., Kahraman, M. and Tektas, S. (1996) Extradural Haematoma: Analysis of 190 Cases. Turkish Neurosurgery, 6, 63-67.

[6] Özkan, Ü., Kemaloglu, S., Özates, M., Güzel, A. and That, M. (2007) Analyzing Extradural Haematomas: A Retrospective Clinical Investigation. Dicle Tip Dergisi, 34, 14-19.

[7] Khaled Chowdhury, S.M.N., Tarikul Islam, K.M., Mahmood, E. and Hossain, S.S. (2012) Extradural Haematoma in 
Children: Surgical Experience and Prospective Analysis of 170 Cases. Turkish Neurosurgery, 22, 39-43. http://dx.doi.org/10.5137/1019-5149.JTN.4550-11.1

\section{Abbreviations}

CT: Computed tomography; EDH: Epidural or extradural hematoma; GCS: Glasgow coma scale; GOS: Glasgow outcome score; LOC: Loss of consciousness; TBI: Traumatic brain injury; UHC: University Hospital Center.

\section{Submit or recommend next manuscript to SCIRP and we will provide best service for you:}

Accepting pre-submission inquiries through Email, Facebook, Linkedin, Twitter, etc A wide selection of journals (inclusive of 9 subjects, more than 200 journals)

Providing a 24-hour high-quality service

User-friendly online submission system

Fair and swift peer-review system

Efficient typesetting and proofreading procedure

Display of the result of downloads and visits, as well as the number of cited articles

Maximum dissemination of your research work

Submit your manuscript at: http://papersubmission.scirp.org/ 